\title{
Toward Isolation of Palytoxins: Liquid Chromatography Coupled to Low- or High-Resolution Mass Spectrometry for the Study on the Impact of Drying Techniques, Solvents and Materials
}

\author{
Antonia Mazzeo ${ }^{1}$, Michela Varra ${ }^{1}$, Luciana Tartaglione ${ }^{1,2, *(\mathbb{D},}$, Patrizia Ciminiello ${ }^{1}$, Zita Zendong ${ }^{3}$, \\ Philipp Hess ${ }^{3}$ iD and Carmela Dell'Aversano ${ }^{1,2} \mathbb{D}$
}

1 Department of Pharmacy, School of Medicine and Surgery, University of Napoli Federico II, Via D. Montesano 49, 80131 Napoli, Italy; antonia.mazzeo@unina.it (A.M.); varra@unina.it (M.V.); ciminiel@gmail.com (P.C.); dellaver@unina.it (C.D.)

2 CoNISMa-National Inter-University Consortium for Marine Sciences, Piazzale Flaminio 9, 00196 Rome, Italy 3 Ifremer, DYNECO, Laboratoire Phycotoxines, Rue de l'Île d'Yeu, 44311 Nantes, France; Zita.Zendong@effem.com (Z.Z.); Philipp.Hess@ifremer.fr (P.H.)

* Correspondence: luciana.tartaglione@unina.it

check for updates

Citation: Mazzeo, A.; Varra, M.; Tartaglione, L.; Ciminiello, P.; Zendong, Z.; Hess, P.; Dell'Aversano,

C. Toward Isolation of Palytoxins: Liquid Chromatography Coupled to Low- or High-Resolution Mass Spectrometry for the Study on the Impact of Drying Techniques, Solvents and Materials. Toxins 2021, 13, 650. https://doi.org/10.3390/ toxins13090650

\section{Received: 30 July 2021}

Accepted: 10 September 2021

Published: 14 September 2021

Publisher's Note: MDPI stays neutral with regard to jurisdictional claims in published maps and institutional affiliations.

Copyright: (c) 2021 by the authors. Licensee MDPI, Basel, Switzerland. This article is an open access article distributed under the terms and conditions of the Creative Commons Attribution (CC BY) license (https:// creativecommons.org/licenses/by/ $4.0 /)$.

\begin{abstract}
Palytoxin (PLTX) and its congeners are emerging toxins held responsible for a number of human poisonings following the inhalation of toxic aerosols, skin contact, or the ingestion of contaminated seafood. Despite the strong structural analogies, the relative toxic potencies of PLTX congeners are quite different, making it necessary to isolate them individually in sufficient amounts for toxicological and analytical purposes. Previous studies showed poor PLTX recoveries with a dramatic decrease in PLTX yield throughout each purification step. In view of a large-scale preparative work aimed at the preparation of PLTX reference material, we have investigated evaporation as a critical—although unavoidable—step that heavily affects overall recoveries. The experiments were carried out in two laboratories using different liquid chromatography-mass spectrometry (LC-MS) instruments, with either unit or high resolution. Palytoxin behaved differently when concentrated to a minimum volume rather than when evaporated to complete dryness. The recoveries strongly depended on the solubility as well as on the material of the used container. The LC-MS analyses of PLTX dissolved in aqueous organic blends proved to give a peak intensity higher then when dissolved in pure water. After drying, the PLTX adsorption appeared stronger on glass surfaces than on plastic materials. However, both the solvents used to dilute PLTX and that used for re-dissolution had an important role. A quantitative recovery (97\%) was achieved when completely drying $80 \%$ aqueous EtOH solutions of PLTX under $\mathrm{N}_{2}$-stream in Teflon. The stability of PLTX in acids was also investigated. Although PLTX was quite stable in $0.2 \%$ acetic acid solutions, upon exposure to stronger acids $(\mathrm{pH}<2.66)$, degradation products were observed, among which a PLTX methyl-ester was identified.
\end{abstract}

Keywords: palytoxin; LC-HRMS; evaporation; stability; palytoxin methyl ester

Key Contribution: The effect of the solvent, container material, type of evaporation device and degree of concentration on PLTX recovery have been systematically investigated. In addition, since acids are often used in the extraction and in the chromatographic separation of closely related analogues, the stability of PLTX in acids over time, heat treatment and the following evaporation has been studied, pointing out the formation of potential artifacts.

\section{Introduction}

Palytoxin (PLTX) is a very potent marine toxin contained in several species of marine zoanthids belonging to the genus Palythoa [1,2] as well as in cyanobacterial blooms 
Trichodesmium sp. [3]. A number of PLTX analogues have been detected in sub-tropical microalgae belonging to the genus Ostreopsis and named ovatoxins from O. cf. ovata and Ostreopsis fattorussoi, ostreocins from O. siamensis and mascarenotoxins from O. mascarenensis [4-6]. Palytoxin and its congeners are large molecules of polyketide nature with a molecular weight $>2600 \mathrm{Da}$, featuring a polyhydroxylated and a partially unsaturated aliphatic chain containing assorted cyclic ether, amine, amide and ketal/hemiketal functionalities (Figure S1).

Although the first cases of poisonings referred to the ingestion of PLTX contaminated seafood [7], several cases of respiratory poisonings and/or skin injuries have been reported in beachgoers during massive blooms of $O$. cf. ovata [8] as well as in aquarium hobbyists from incidental contact with PLTX-producing Palythoa spp. [9,10]. The symptom similarities between the Ostreopsis- and Palythoa-related poisonings suggested that PLTXs are the etiological agents and the respiratory toxicity of PLTXs was successively proven by the exposure of rats to aerosolized PLTX preparations $[9,11]$. Nevertheless, the toxicity studies performed on a few PLTX congeners showed that, despite small diversity in structure or even in stereo-structure, their relative toxic potencies might be quite different either in vivo or in vitro [10,12-16]. As a consequence, the need exists to evaluate the individual toxicity of each PLTX congener in order to carry out reliable structure-activity relationship studies and assess the real hazard they present to humans. The availability of sufficient amounts of well characterized reference material is an important pre-requisite to obtain toxicity data. To this aim, an isolation procedure for the quantitative recovery of each PLTX congener should be developed and the stability of PLTX under different conditions should be evaluated.

Previous work by Ciminiello et al. on the isolation of ovatoxin-a, the main PLTX-like toxic component of $O$. cf. ovata [17], although successful in recovering $700 \mu \mathrm{g}$ of pure toxin from 80 liters of algal culture, only provided an overall recovery of about $12 \%$ as the result of extraction, four chromatographic and multiple evaporation steps. Similarly, Brissard et al. [18] obtained an 85\% recovery of ovatoxins after a single chromatography; however, the same authors only recovered a third of the expected toxins after complete evaporation. In the evaluation of polymeric sorbents for the passive sampling of marine toxins from seawater, Zendong et al. also reported poor recoveries for ovatoxin-a [19]. Even the isolation of assorted PLTXs from P. tuberculosa required $45 \mathrm{~kg}$ of starting material to end up with only $4 \mathrm{mg}$ of pure individual toxins [2]. There is no experimental evidence to explain whether the low recoveries of PLTX and its congeners are due to the instability of the compounds in solution or to the irreversible adsorption to materials or even to other uncontrolled factors. Only Taylor et al. suggested a non-specific binding of PLTX to polyethylene tubing [20].

In view of large-scale isolation work, the causes underlying the significant losses in PLTX need to be clarified. Since the evaporation step is unavoidable in any isolation protocol, in this study, we investigated the recoveries of PLTX in different samples under various experimental conditions including the use of different evaporation systems, as well as complete drying versus concentration to a minimum volume. The influence on the toxin recovery of various solvents (aqueous or organic) and of the most common container materials (different qualities of glass and plastics) was investigated. Based on the possibility to add acids in mobile phases to be used in some of the chromatographic steps, the stability of PLTX under various acidic conditions was also investigated. The experiments were carried out in two laboratories using different LC-MS instruments operating at unit and high resolution. For the sake of clarity, a schematic summary of the overall experiments has been reported in Table 1. 
Table 1. Summary of the experiments and conditions used for analyses of PLTX.

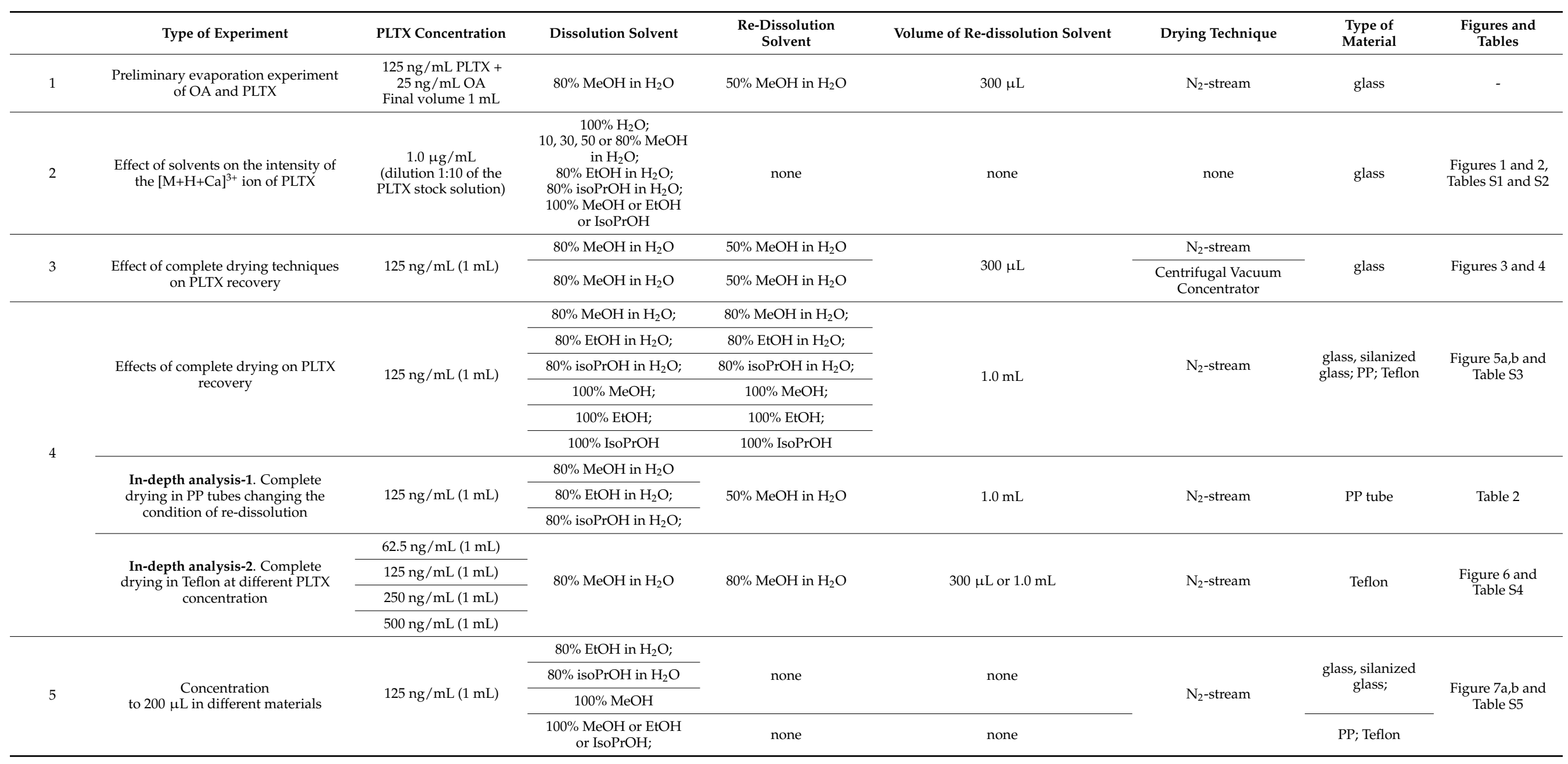




\section{Results and Discussion}

\subsection{Preliminary Evaporation Experiment of $O A$ and PLTX}

In order to substantiate the heavy toxin losses reported within the purification of PLTXs [17-19] and to exclude that they were due to an operators' systematic bias, a preliminary evaporation experiment was performed on a mixture of PLTX and okadaic acid (OA), a diarrhetic shellfish poisoning toxin that was used as reference to compare drying down recoveries. An equimolar solution of PLTX and OA in $80 \%$ aqueous $\mathrm{MeOH}-$ the solvent most employed to extract PLTXs from mussels [21,22] and seawater [9]—was evaporated to dryness under $\mathrm{N}_{2}$-stream. A statistically significant lower recovery was measured for PLTX $(62 \pm 6 \% ; n=3)$ than that obtained for OA $(103 \pm 2 \% ; n=3)$. This clearly confirmed the previously reported data [17-19] and suggested that at least one of the reasons for toxin loss is related to the drying down step, which, therefore, represents a key step to optimize within the isolation work.

\subsection{Effect of Solvents on the Intensity of the $[\mathrm{M}+\mathrm{H}+\mathrm{Ca}]^{3+}$ Ion of PLTX}

The $[\mathrm{M}+\mathrm{H}+\mathrm{Ca}]^{3+}$ ion is the base peak in the full scan HRMS spectrum of PLTX and its congeners analyzed under the conditions described above, and it is the main ion used for quantitative purposes. In order to identify the effect of the solvent condition on the intensity of the $[\mathrm{M}+\mathrm{H}+\mathrm{Ca}]^{3+}$ ion, PLTX stock solution was diluted (1:10) in different solvent mixtures (Table 1 ) in glass vials and analyzed using LC-HRMS $2 \mathrm{~h}$ after preparation (Figure 1 and Table S2).

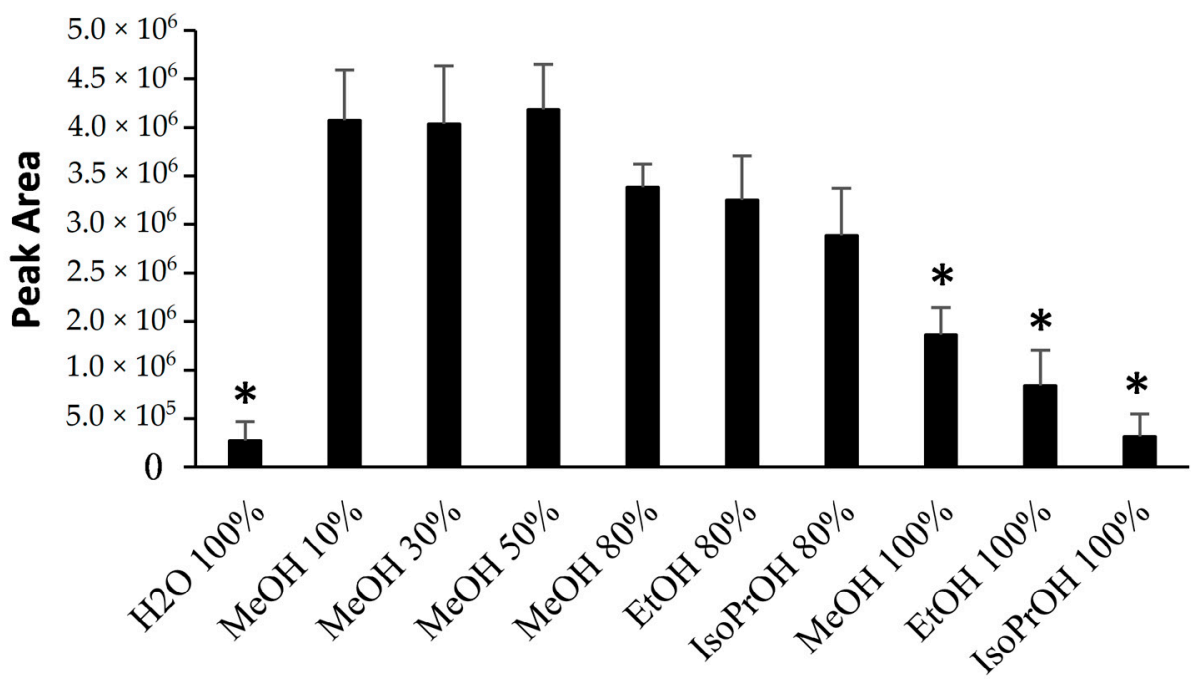

Figure 1. LC-HRMS response (peak areas of the Extracted Ion Chromatogram at $\mathrm{m} / \mathrm{z}$ 906.4824) of PLTX $(1.0 \mu \mathrm{g} / \mathrm{mL})$ stored in various solvents mixtures in glass vials. Error bars represent standard deviation $(n=3)$. Response in $50 \%$ aqueous $\mathrm{MeOH}$ was taken as reference. ${ }^{*}$ denotes statistically significant difference, $p<0.001$.

The highest responses were obtained when PLTX was diluted in 10\%, 30\% and 50\% aqueous $\mathrm{MeOH}$ with no significant difference among the three blends. A decreasing trend in the response was observed for the $80 \%$ aqueous blends, in the order $80 \% \mathrm{MeOH}>80 \%$ $\mathrm{EtOH}>80 \%$ IsoPrOH. Taking the PLTX response in 50\% aqueous $\mathrm{MeOH}$ as a reference (control), a significantly lower response $(p<0.001)$ was observed for PLTX dilutions in pure organic solvents $(\mathrm{MeOH}>\mathrm{EtOH}>$ IsoPrOH). A 93\% decrease in the PLTX response versus the control was also recorded for PLTX in water, suggesting that an appropriate amount of organic modifier appears suitable for the detection of PLTX using LC-HRMS.

The low PLTX response in water could be due to the formation of ion species different from those monitored in the LC-HRMS experiments, such as a PLTX dimer [23]. To test this hypothesis, the full HRMS spectra of PLTX standard $(10.0 \mu \mathrm{g} / \mathrm{mL})$ in pure water 
(Figure S2) and in 50\% aqueous $\mathrm{MeOH}$ were acquired (Figure 2). In both samples, the presence of a PLTX dimer $[2 \mathrm{M}+\mathrm{H}+\mathrm{Ca}]^{3+}$ at $m / z 1799.3102(\Delta=0.479 \mathrm{ppm})$ and a PLTX trimer $[3 \mathrm{M}+3 \mathrm{H}+\mathrm{Ca}]^{5+}$ at $m / z 1615.6828(\Delta=-0.997 \mathrm{ppm})$ emerged (Figure 2$)$, together with the monomer $[\mathrm{M}+\mathrm{H}+\mathrm{Ca}]^{3+}$ and $\left[\mathrm{M}+2 \mathrm{H}_{-} \mathrm{H}_{2} \mathrm{O}\right]^{2+}$ at $m / z 906.4824$ and $m / z 1331.2412$, respectively. The PLTX monomer represented the dominant form in the spectra of both samples, with the dimer accounting only for $2.6 \%$ (in water) and $1.6 \%$ (in $50 \%$ aqueous $\mathrm{MeOH})$ of the total ion species contained in the spectra. Even when assuming that the dimer and trimer have reduced ionization yield, this suggested that the ionization behavior of PLTX in the two solutions was similar and that the dimer/trimer-formation did not significantly affect the reduction in response. Overall, these observations suggested that another issue deserves attention to interpret the low LC-HRMS response of PLTX in water and we focused on the hypothesis of the adsorption of PLTX on the container surfaces [20].
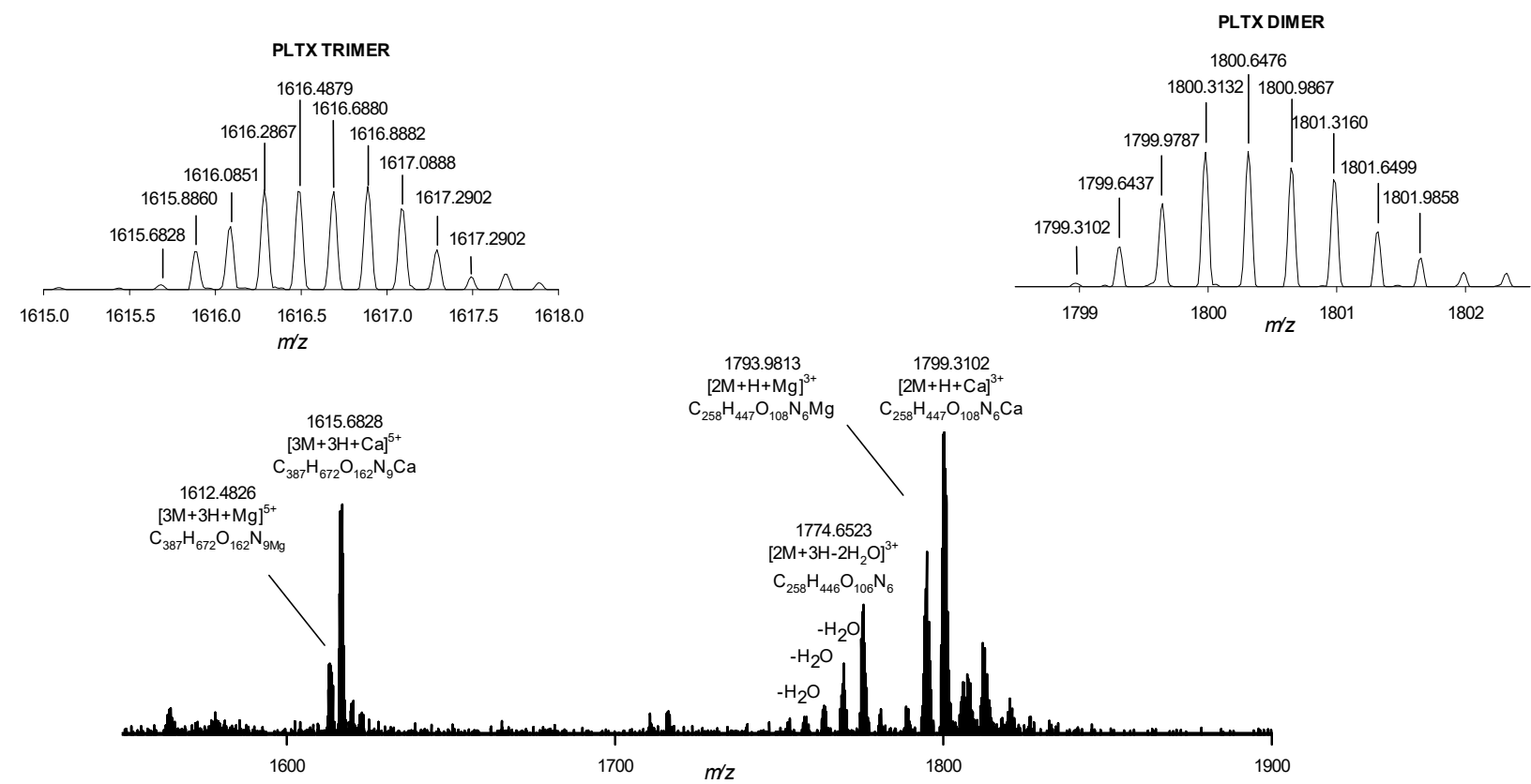

Figure 2. Full HRMS spectrum of PLTX ( $m / z$ 1510-1900) where PLTX dimer and trimer ion clusters appear dominated by $[2 \mathrm{M}+\mathrm{H}+\mathrm{Ca}]^{3+}$ and $[3 \mathrm{M}+3 \mathrm{H}+\mathrm{Ca}]^{5+}$ ions, respectively. Formula assigned to monoisotopic ion peaks are reported together with the isotopic ion patterns of the most intense ions.

Previous studies on the adsorption of organic molecules on a silica surface revealed that the hydration forces, originated from the water structure in the vicinity of silica, are disrupted in the presence of methanol. Methanol adsorbs on silica by the displacement of water molecules [24,25]. Furthermore, ethanol also adsorbs on silica to a lesser extent than methanol. This phenomenon could account for our experimental data suggesting that the PLTX adsorption occurs by an interaction between PLTX itself, or its water solvated form, with hydrated glass. The $10 \%$ organic component in methanol aqueous blends, disrupting the water-glass layer, inhibits PLTX adsorption. Therefore, the intensity of the $[\mathrm{M}+\mathrm{H}+\mathrm{Ca}]^{3+}$ ion of PLTX, strongly increases (up to 13-fold) in water-based organic blends compared to PLTX in $100 \%$ water (Table S2). The increase in the percentage of $\mathrm{MeOH}$ in aqueous blends from 10 to $50 \%$ (Figure 1) did not result in a further increase in the intensity of the PLTX LC-HRMS signal. If we also include the percentage of methanol contained in the PLTX stock solution, the PLTX sample labelled as 10\% methanol in water was actually $15 \%$ methanol in water and the obtained results are in full agreement with previous data that show that about $15 \% \mathrm{MeOH}$ in water is sufficient to disrupt the water-silica layer [24-26].

The behavior of PLTX in water shows similarity to that of microparticles on solid surface where the liquid meniscus formed around the contact area between the microparticle 
and the surface, due to the condensation of water, results in an additional capillary force between the two materials [26].

Moreover, the relative intensity of the PLTX $[\mathrm{M}+\mathrm{H}+\mathrm{Ca}]^{3+}$ ion in organic-aqueous mixtures containing more than $50 \%$ organic solvent as well as in pure organic solvent decreased according to the dielectric constant of the organic component $(\mathrm{MeOH}>\mathrm{EtOH}>\mathrm{IsOPrOH})$, thus suggesting that an aqueous mixture of an opportune organic solvent promotes its dissolution.

In conclusion, handling PLTX requires that even a simple dilution pre-treatment should be carefully performed and that, despite the high polarity of the toxin, the low response (Figure 1) in 100\% water using glass vials leads to consider this condition inappropriate.

\subsection{Effect of Drying Techniques on PLTX Recovery}

PLTX solutions (Table 1 , condition 3, $80 \%$ aqueous $\mathrm{MeOH}$ ) were dried down using $\mathrm{N}_{2}$-stream or a Centrifugal Vacuum Concentrator in glass vials without a cap (as routinely conducted) over one day. Based on the results reported in Figure 1, after drying down, each PLTX residue was re-dissolved using 50\% aqueous MeOH. The LC-MS analyses (Figure 3) showed that the PLTX recoveries were quite similar using $\mathrm{N}_{2}$-stream $(62 \pm 6 \%)$ and a Centrifugal Vacuum Concentrator $(64 \pm 5 \%)$. This suggested that the PLTX recovery is affected to the same extent by both evaporation techniques. Due to the way in which the two techniques are conceived, it cannot be excluded that within the dry-down processes, the above-described strong solvent-mediated adsorption forces trigger incipient motions from which a partial loss of PLTX could be favored [8-10,26].

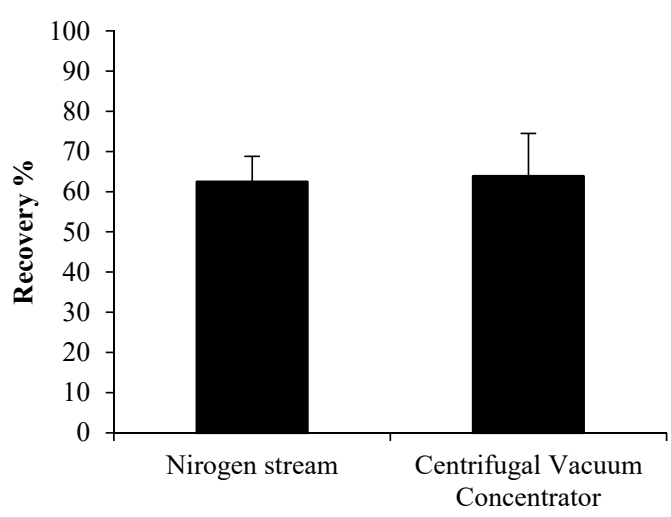

Figure 3. Palytoxin Recoveries after complete drying under Nitrogen stream and Centrifugal Vacuum Concentrator (see Table 1 for experimental details).

However, the recovery being unsatisfactory for multi-step purification from natural matrices, we then explored the drying down using different materials for tubes and/or vials.

\subsection{Complete Drying in Different Materials}

The interaction between the tube materials and the PLTX dissolved in pure $\mathrm{MeOH}$, $\mathrm{EtOH}$ and IsoPrOH, as well as $80 \%$ aqueous blends of each of the above solvents, was investigated, performing complete drying experiments under $\mathrm{N}_{2}$-stream in normal and silanized glass vials as well as in PP and Teflon tubes (Figure 4a,b and Table 1 and Table S3). The highest recoveries were obtained when PLTX was dried down in Teflon tubes, with a $97 \%$ recovery obtained for the $80 \%$ aqueous EtOH sample. In both plastic materials, the recoveries in pure organic solvents $(\mathrm{MeOH}>\mathrm{EtOH}>>$ IsoPrOH) paralleled the trend of the data described in Section 2.2 (Figures 1 and 4a). In both glass materials (Figure 4b), unsatisfactory recoveries were obtained for all the tested solvents. PLTX was not detected after drying down in pure $\mathrm{EtOH}$ and $\mathrm{IsoPrOH}$, with only $33 \%$ being recovered after drying down in $\mathrm{MeOH}$. Even considering the good solubility of PLTX in aqueous blends, no more than $58 \%$ could be recovered after drying it down from aqueous mixtures, thus supporting the hypothesis above-described in Section 2.2. 


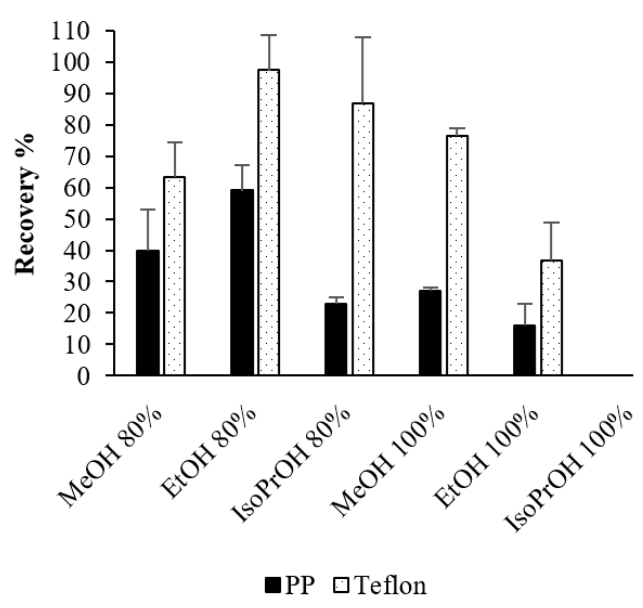

(a)

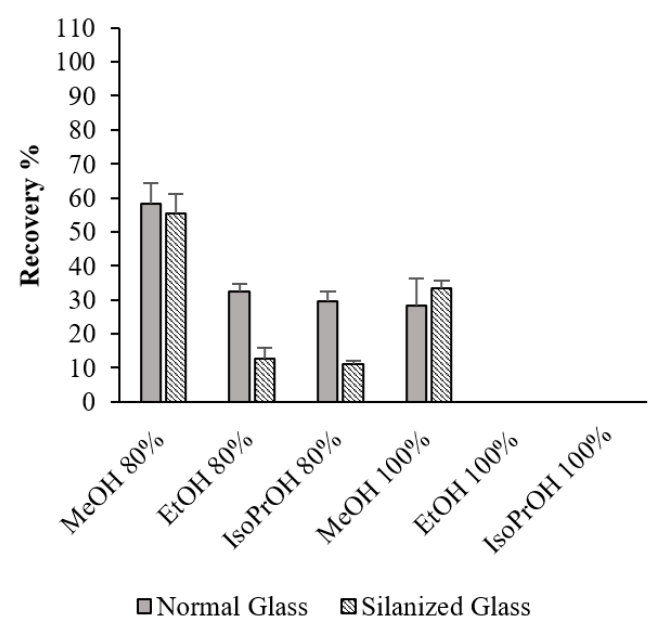

(b)

Figure 4. Recoveries of PLTX (125 ng/mL, $1.0 \mathrm{~mL}$ ) following complete drying performed with N2-stream in (a) PP and Teflon tubes and (b) normal and silanized glass vials. The residues were re-dissolved in $300 \mu \mathrm{L}$ of the initial solvent/blend. Recoveries are expressed in $\% \pm$ RSD as mean of three different replicates.

The PLTX recovery in PP tubes and silanized glass vials appears similar to that obtained diluting PLTX in different solvents or blends (see Section 2.2). To test this hypothesis, we also performed the complete drying of a new set of PLTX samples in PP tubes using $\mathrm{MeOH}, \mathrm{EtOH}$ and $\mathrm{IsoPrOH}$ and $80 \%$ aqueous blends of each of such solvents as starting solvents and re-dissolving all the samples in $50 \%$ aqueous $\mathrm{MeOH}$. The results are shown in (Table 2). As expected, higher recoveries were obtained for all the samples when redissolved in 50\% MeOH. However, overall recoveries were still unsatisfactory (40-61\%), thus suggesting that adsorption could also occur on the surface of these two types of materials, mainly through Van der Waals interactions.

Table 2. Complete drying performed with $\mathrm{N}_{2}$-stream of PLTX $(125 \mathrm{ng} / \mathrm{mL}, 1.0 \mathrm{~mL})$ in polypropylene (PP) tubes in different solvents/blends. Samples are re-dissolved in the same initial solvent/blend or in $50 \%$ aqueous $\mathrm{MeOH}$. Recoveries (\% $\pm \mathrm{RSD}$ ) are calculated as mean of three different replicates. * not detected.

\begin{tabular}{ccc}
\hline PLTX in & \multicolumn{2}{c}{$\begin{array}{c}\text { Complete Drying in PP and } \\
\text { Re-Dissolution in }\end{array}$} \\
\hline & Original Solvent & $\mathbf{5 0 \%}$ Aqueous $\mathbf{M e O H}$ \\
\hline $80 \% \mathrm{MeOH}$ in $\mathrm{H}_{2} \mathrm{O}$ & $40 \pm 13$ & $56 \pm 11$ \\
$80 \% \mathrm{EtOH}$ in $\mathrm{H}_{2} \mathrm{O}$ & $59 \pm 8$ & $61 \pm 4$ \\
$80 \% \mathrm{IsoPrOH}$ in $\mathrm{H}_{2} \mathrm{O}$ & $23 \pm 2$ & $60 \pm 6$ \\
$\mathrm{MeOH} \mathrm{100 \%}$ & $27 \pm 1$ & $42 \pm 8$ \\
$\mathrm{EtOH} 100 \%$ & $16 \pm 7$ & $46 \pm 9$ \\
IsoPrOH $100 \%$ & $\mathrm{nd}^{*}$ & $40 \pm 13$ \\
\hline
\end{tabular}

Due to the positive results obtained in Teflon tubes, and considering the different results obtained for $80 \%$ aqueous $\mathrm{MeOH}$ or $\mathrm{EtOH}$ blends (Figure $4 \mathrm{a}$ ), we also explored PLTX recoveries following drying down under $\mathrm{N}_{2}$-stream in Teflon tubes using different concentration levels $(62.5,125,250$ and $500 \mathrm{ng} / \mathrm{mL}$ ) in $80 \%$ aqueous $\mathrm{MeOH}$ (Figure 5 and Table S4). The residues were re-dissolved, either in $300 \mu \mathrm{L}$ or in $1 \mathrm{~mL}$ of $50 \%$ aqueous $\mathrm{MeOH}$. The recoveries increased with the concentration, with the highest recovery for PLTX $(86 \%)$ being obtained at the highest concentration and the lowest recoveries (about $47 \%)$ at the lowest concentrations $(<250 \mathrm{ng} / \mathrm{mL})$. 


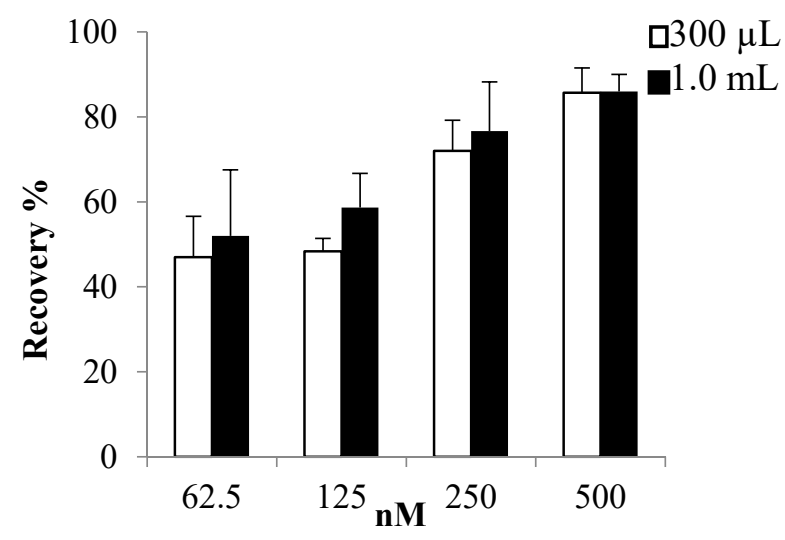

Figure 5. Recoveries of PLTX at different initial concentration (initial volume $1.0 \mathrm{~mL}$, in $80 \%$ aqueous $\mathrm{MeOH}$ ) following complete drying performed with $\mathrm{N}_{2}$ stream in Teflon tubes. The samples were re-dissolved in $300 \mu \mathrm{L}$ or $1.0 \mathrm{~mL}$ of $50 \%$ aqueous $\mathrm{MeOH}$. Recoveries are expressed in $\% \pm \mathrm{RSD}$ as mean of three different replicates.

Increasing the re-dissolution volume from $300 \mu \mathrm{L}$ to $1.0 \mathrm{~mL}$, recoveries improved by $5-11 \%$ at the lowest concentration levels ( 62.5 to $250 \mathrm{ng} / \mathrm{mL}$ ), while no difference was observed at $500 \mathrm{ng} / \mathrm{mL}$.

Despite the fact that the adsorption forces are strongly reduced on Teflon tubes, some PLTX loss through incipient motions could occur according to the used drying technique. From the data reported in Table S4, it emerges that PLTX loss reaches its maximum of 60-70 ng, already at a PLTX concentration of $125 \mathrm{ng} / \mathrm{mL}$. However, at the lowest explored PLTX concentration $(62.5 \mathrm{ng} / \mathrm{mL})$, only $30 \mathrm{ng}$ of PLTX were lost.

\subsection{Concentration in Different Materials}

In order to further explore the phenomena occurring during drying down, we chose to stop some of the above described experiments that gave the worst results (Figure 4) to the intermediate step of concentration (not evaporating to dryness but concentrating to a smaller volume). Thus, the recovery after concentrating PLTX samples ( $125 \mathrm{ng}, 1.0 \mathrm{~mL})$ in $100 \%$ organic solvents to $200 \mu \mathrm{L}$ under $\mathrm{N}_{2}$-stream was evaluated in PP and Teflon tubes (Figure 6a). Similarly, the recovery of PLTX, $125 \mathrm{ng}$ in $1.0 \mathrm{~mL}$ of $80 \% \mathrm{EtOH}$ or isoPrOH, was assessed after concentrated to $200 \mu \mathrm{L}$ under $\mathrm{N}_{2}$-stream using normal and silanized glass vials (Figure $6 \mathrm{~b}$ and Table S5). As expected, the fact that at the end of the process, PLTX was still kept in the solution, limited its adsorption on the surfaces (tubes/vials) that could catalyze the deleterious PLTX aggregation phenomena. In particular, we hypothesize that, since PLTX is a high molecular weight compound containing both polar and hydrophobic groups, its behavior in solution could be affected by the environmental conditions in a similar manner as that reported for proteins. Actually, proteins can aggregate into particles because of conformational changes caused by different mechanical and chemical-physical stress conditions ( $\mathrm{pH}$, temperature, pressure, vortexing, etc.) including surface adsorption, which, in turn, can promote aggregate formation $[27,28]$. This resulted in a higher recovery than that obtained after complete drying (Figure 4). 


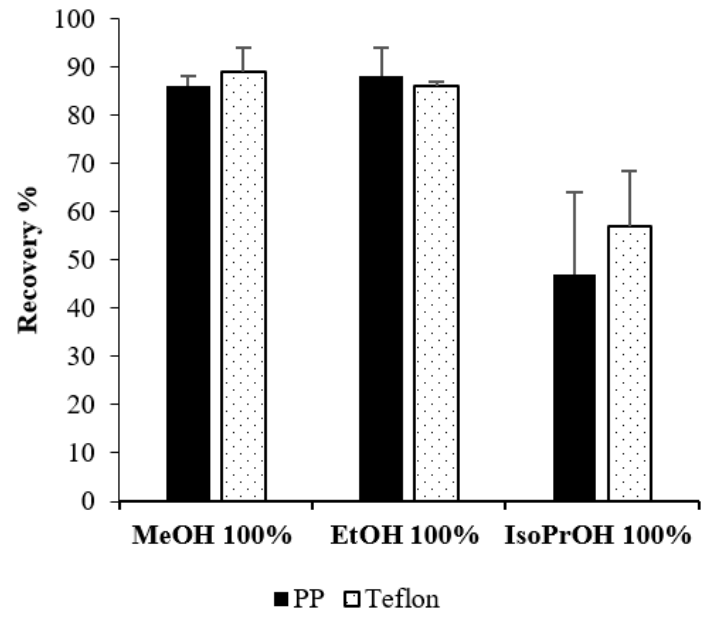

(a)

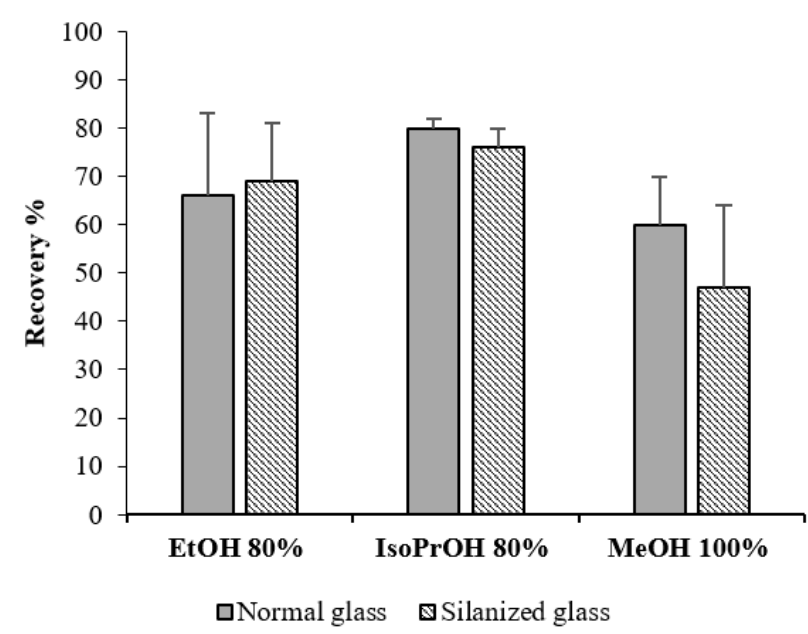

(b)

Figure 6. Recoveries of PLTX ( $125 \mathrm{ng} / \mathrm{mL}, 1.0 \mathrm{~mL}$ ) following concentration to $200 \mu \mathrm{L}$ under $\mathrm{N}_{2}$-stream in (a) PP and Teflon tubes and (b) normal and silanized glass vials. Recoveries are expressed in $\% \pm$ RSD as mean of three different replicates.

\subsection{Study on Stability of PLTX in Acids}

The extraction of PLTXs from algae and seawater is often performed using acidic conditions $[9,29]$. Furthermore, acids are frequently used in chromatography to improve the resolution of closely eluting analogs [30]. Therefore, the potential degradation of PLTX in acidic conditions was investigated. The tested acidic concentrations were those routinely used for PLTX purification $[9,17,29]$. Solutions of PLTX with additions of either acetic acid (AA) ( $\mathrm{pH} 3.25)$, formic acid (FA) ( $\mathrm{pH}$ 2.66), or trifluoro acetic acid (TFA) (pH 1.20) were analyzed at day 0 and at day 14 versus a control (PLTX in $80 \%$ aqueous $\mathrm{MeOH}$ ). No statistically significant difference was measured at day 0 among the different treatments. At day 14, while no variations were observed for PLTX in AA versus control, a 64 and a 29\% decrease in the PLTX signal was measured for the samples in TFA and FA, respectively. This suggested that exposure to strong acidic conditions $(\mathrm{pH} \leq 2.66)$ causes PLTX degradation (Table 3).

Table 3. Percentage of PLTX and its derivative at day 0 and 14 in all acidified samples versus control.

\begin{tabular}{|c|c|c|c|c|c|c|c|c|}
\hline & \multirow{2}{*}{\multicolumn{2}{|c|}{$\begin{array}{c}80 \% \text { Aqueous } \mathrm{MeOH} \\
\text { Control }\end{array}$}} & \multicolumn{6}{|c|}{$80 \%$ Aqueous $\mathrm{MeOH}$ with } \\
\hline & & & \multicolumn{2}{|c|}{$0.2 \%$ AA } & \multicolumn{2}{|c|}{$2 \%$ FA } & \multicolumn{2}{|c|}{$0.1 \%$ TFA } \\
\hline & PLTX\% & $\begin{array}{c}\text { PLTX } \\
\text { Derivative } \%\end{array}$ & PLTX\% & $\begin{array}{c}\text { PLTX } \\
\text { Derivative } \%\end{array}$ & PLTX\% & $\begin{array}{c}\text { PLTX } \\
\text { Derivative } \%\end{array}$ & PLTX\% & $\begin{array}{c}\text { PLTX } \\
\text { Derivative\% }\end{array}$ \\
\hline Day 0 & 100 & 0 & 100 & 0 & 89 & 11 & 84 & 16 \\
\hline Day 14 & 100 & 0 & 94 & 6 & 61 & 39 & 37 & 63 \\
\hline
\end{tabular}

The degradation in TFA and FA was even more evident following either complete drying under $\mathrm{N}_{2}$-stream (Figure 7a) or heat treatment (Figure 7b). The complete drying of PLTX in TFA and FA provided recoveries of 28 and $58 \%$, respectively, likely as a consequence of a progressive decrease in the $\mathrm{pH}$ during the evaporation. Heat treatment $\left(60^{\circ} \mathrm{C}\right.$, $1 \mathrm{~h}$ ) led to a dramatic loss of PLTX, with a recovery of $16 \%$ in TFA. 


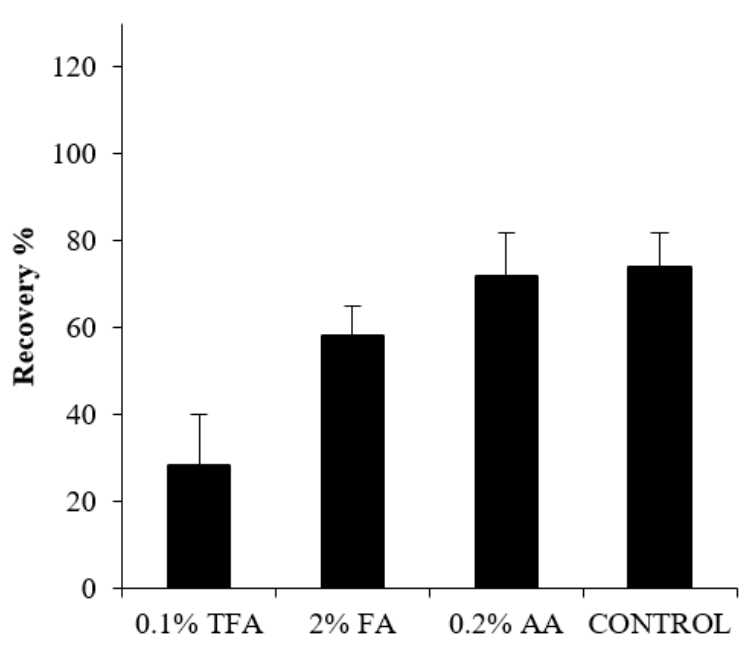

(a) After evaporation

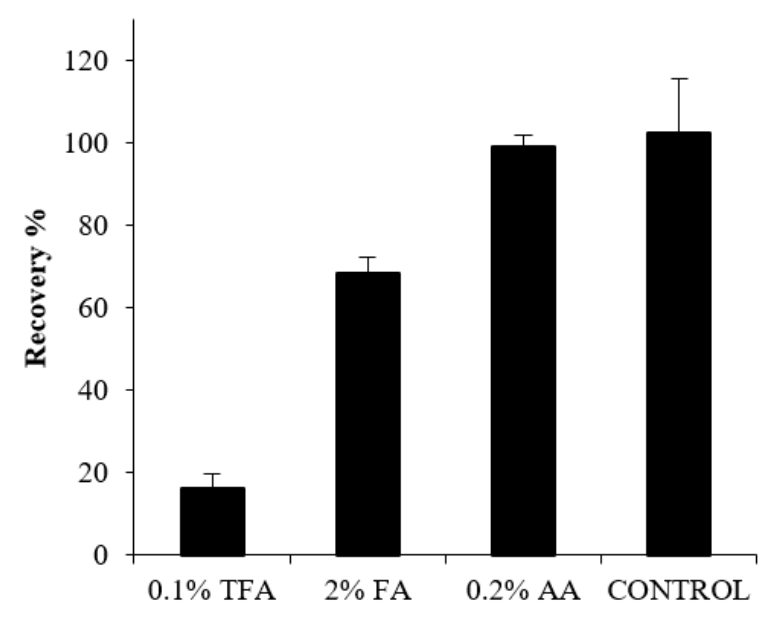

(b) $60^{\circ} \mathrm{C}$ for $1 \mathrm{~h}$

Figure 7. Recoveries of PLTX (125 ng) in $80 \%$ aqueous MeOH with the addition of $0.2 \%$ acetic acid (AA), $0.1 \%$ trifluoroacetic acid (TFA) and $2 \%$ formic acid (FA) and no acid (control) following (a) complete drying in Teflon tubes and subsequent re-dissolution in $1 \mathrm{~mL}$ of $80 \%$ aqueous $\mathrm{MeOH}$ and $(\mathbf{b})$ heat-treatment $\left(60{ }^{\circ} \mathrm{C}, 1.0 \mathrm{~h}\right)$ in glass tubes. Error bars represent standard deviation from mean of three different replicates.

In both experiments, no significant difference occurred between PLTX in AA and in the control.

The PLTX degradation observed under the stronger acidic conditions can be associated with the presence of several acid-sensitive functionalities in PLTX structure (ketal, hemiketal, amide, enamide, hydroxyl groups). While the opening of the cyclic ketal/hemiketal functional group would not result in mass shifts of the ions in the full HRMS spectrum, hydrolysis of the amide/enamide or the dehydration of alcohols, or even the conversion of the hemiketal at C47 into a methyl ketal would lead to significant mass shifts. In order to investigate the structural changes occurring in PLTX under acidic conditions, we in-depth analyzed the full HRMS spectra of $0.1 \%$ TFA samples at day 0 and 14 (Figure 8 and Figure S3).

The presence of a triply charged ion at $m / z 869.4608$ (monoisotopic at $m / z$ 869.1261, $\mathrm{C}_{124} \mathrm{H}_{216} \mathrm{NO}_{53} \mathrm{Ca}$, RDB 17.5, $\Delta=-2.455 \mathrm{ppm}$ ) eluting in the vicinity of PLTX, emerged in all the acidified samples with the only exception of AA at day 0 and gradually increased overtime and with acid strength (Table 3), thus suggesting it was due to a degradation phenomenon.

The difference of $\mathrm{C}_{5} \mathrm{H}_{8} \mathrm{~N}_{2} \mathrm{O}$ between the molecular formulae of the PLTX derivative $\left(\mathrm{C}_{124} \mathrm{H}_{215} \mathrm{NO}_{53}\right)$ and PLTX $\left(\mathrm{C}_{129} \mathrm{H}_{223} \mathrm{~N}_{3} \mathrm{O}_{54}\right)$ suggested that the structural modification occurs in the A-side terminal of PLTX where $2 \mathrm{~N}$ are present. It is most likely that such a mass difference could derive from either methanolysis of the amide at C1 (Figure S1), or the concomitant hydrolysis of such amide and the formation of a methyl ketal at C47, as outlined for the formation of azaspiracids artifacts [31]. The interpretation of the HRMS 2 spectrum of the PLTX derivative according to Ciminiello et al. [32] allowed us to rule out the latter hypothesis. Indeed, the characteristic B-side fragments (cleavage \#4, \#5, $\# 12, \# 13, \# 15, \# 17)$ and the internal fragments $(\# 4+12, \# 4+15, \# 4+16)$ of the PLTX derivative (Table 4) were superimposable to those of PLTX [32], while all the relevant A-side fragments differed from PLTX for $\mathrm{C}_{5} \mathrm{H}_{8} \mathrm{~N}_{2} \mathrm{O}$. In addition, the characteristic A-side fragment at $\mathrm{m} / \mathrm{z} 327$ (cleavage \#4) of most PLTX congeners [32-35] was totally lacking in the HRMS $^{2}$ spectrum of the PLTX derivative. All of these data pointed toward the structural modifications being located in the C8-A-side terminal and, thus, clearly suggested that the PLTX derivative was the PLTX methyl ester at C1 (Table 4). Its formation, facilitated by strong acidic conditions, could be explained according to a tentative mechanism (Table 4) 
that starts with the protonation of the carbonyl oxygen at $\mathrm{C} 1$, leading to a fully conjugated $\mathrm{N}$-acyliminium cation. In methanol, the presence of such a good leaving group would favor the formation of the methyl ester at $\mathrm{C} 1$. This reaction would occur in place of the reported N-vinyl acetamide hydrolysis that leads to amides and ketones [36].

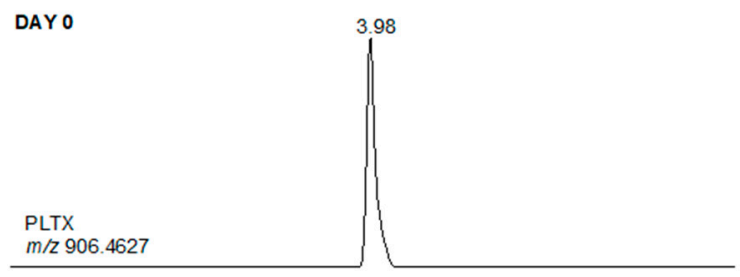

DAY 14
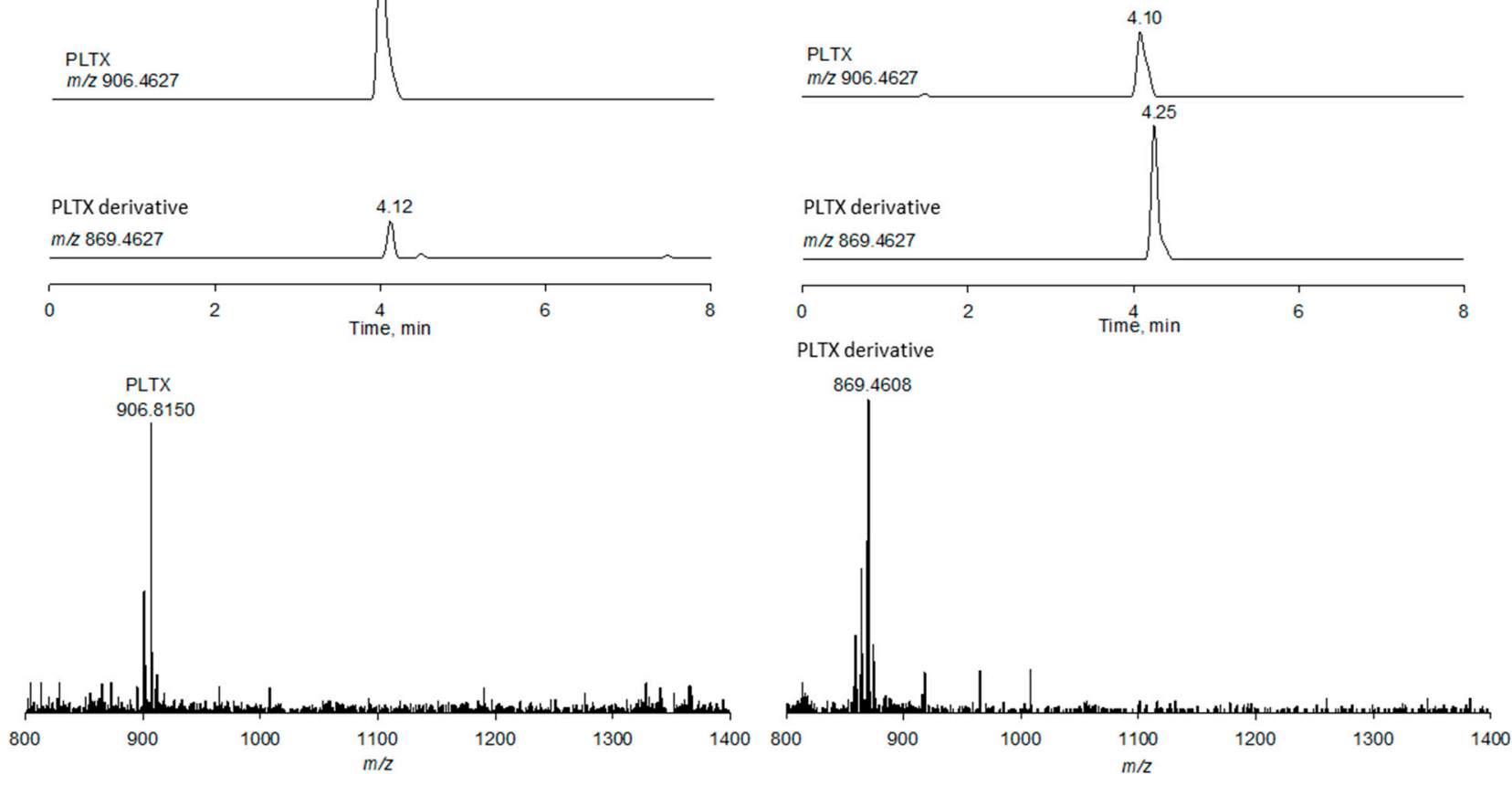

Figure 8. LC-HRMS analysis (flow rate $0.4 \mathrm{~mL} / \mathrm{min}$ ) of PLTX in $80 \%$ aqueous $\mathrm{MeOH}$ with $0.1 \%$ TFA (pH 1.20 ) at day 0 and 14. XICs of $\mathrm{m} / \mathrm{z} 906.4627$ (PLTX) and $\mathrm{m} / \mathrm{z} 869.4627$ (PLTX derivative) and full HRMS spectrum associated to each peak. 


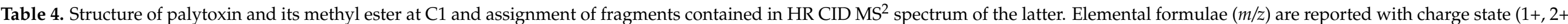
or $3+$ ) and ring double bond equivalent (RDB). Errors were all below 5 ppm. LC HRMS/MS of the PLTX methyl ester tentative mechanism for methyl ester formation.

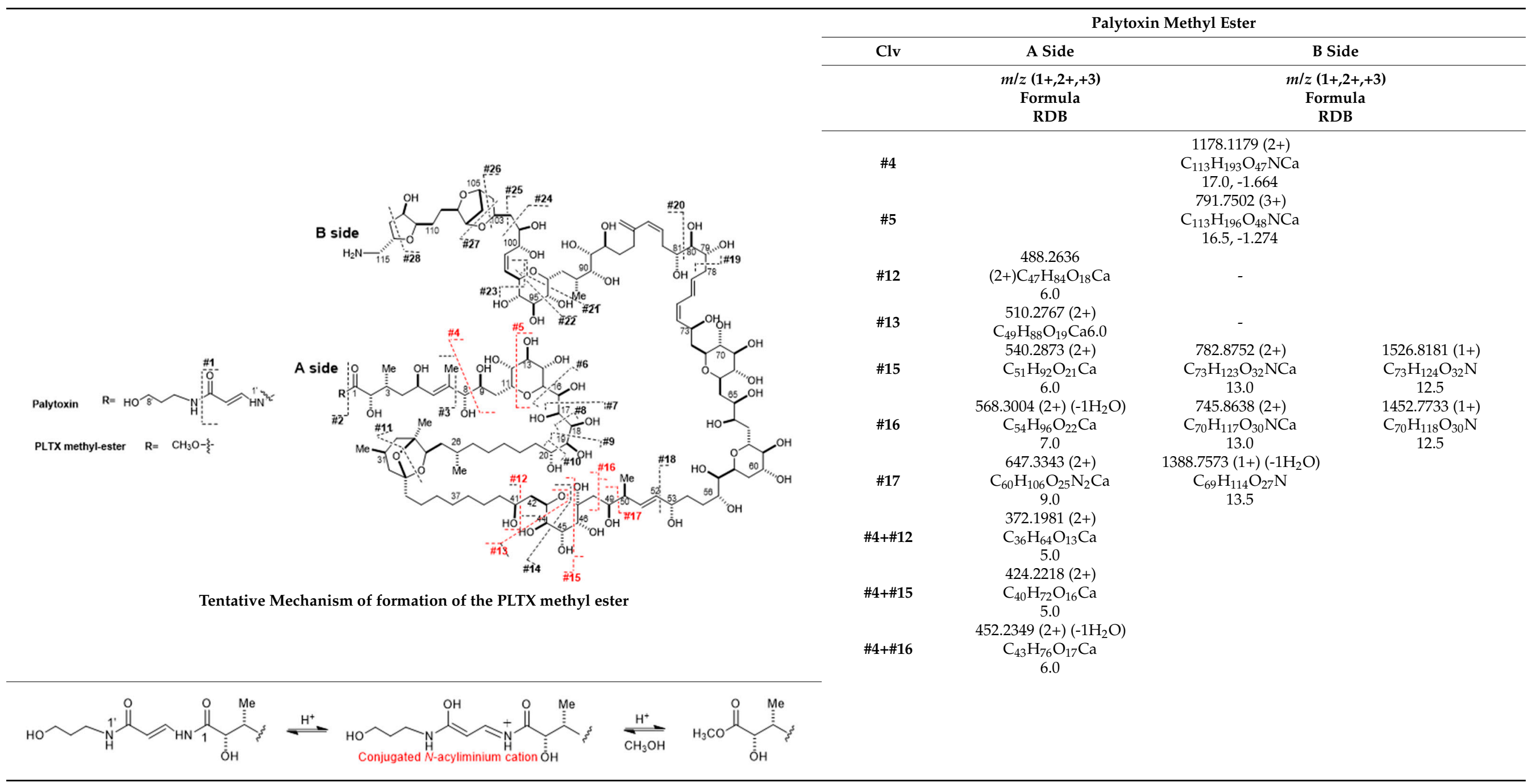




\section{Conclusions}

In view of developing an isolation procedure for the quantitative purification of individual PLTX congeners aimed at the preparation of RMs for each individual analog, we have demonstrated that adsorption on the surface of tubes or vials is a critical issue that may heavily affect the overall recoveries. The phenomenon of adsorption differently affects PLTX recovery depending on the solubility in the solvent system used, with an aqueous organic blend being the best choice in most of the explored cases as compared to pure organic solvents or pure water. Our findings lead to the suspicion that adsorption forces could be mediated by water molecules. The adsorption appeared more pronounced on glass surfaces (either normal or silanized) than on plastic materials (PP or Teflon). The use of a higher percentage of organic component in the blends $(>50 \%)$ strongly reduced the PLTX signals, according to the decreased dielectric constant of the organic component. As PLTX is an amphiphilic molecule, this phenomenon could be related to the decrease in the PLTX solubility in the pure organic modifiers. To confirm this hypothesis, further investigations would be needed to explore the role of solubility in the PLTX losses emerged in this study.

PLTX behaved differently during concentration to a minimum volume than when completely dried down. The recoveries strongly depended on the solvent mixture used to re-dissolve the toxin as well as on the materials in which the drying down was carried out. Glass materials could be used only to concentrate aqueous $\mathrm{EtOH}$ and IsoPrOH solutions. When PLTX is dissolved in $100 \% \mathrm{MeOH}$, complete drying should be avoided and concentration is preferable, either in glass or plastic materials. In general, Teflon provided the best results, both when completely drying aqueous solutions and concentrating organic solutions to a minimum volume. The complete drying of $80 \%$ ethanolic solutions of PLTX in Teflon under Nitrogen stream provided a quantitative recovery $(97 \%)$.

The use of acids for the extraction or the chromatographic separation should be carefully considered. Although PLTX is quite stable in $0.2 \%$ AA solutions at room temperature, in good agreement with some isolation protocols [29], PLTX is not stable in stronger acidic conditions $(\mathrm{pH}<2.66)$ generating degradation products. Among them, the PLTX methyl ester at $\mathrm{C} 1$ was identified.

\section{Materials and Methods}

Statement of human and animal rights: This paper does not raise any concern regarding human and animal rights.

\subsection{Chemicals and Standards}

Organic solvents (HPLC grade) were from AtlanticLabo (Bordeaux, France) and Sigma Aldrich (Steinheim, Germany). Laboratory grade trifluoroacetic acid (TFA), acetic acid (AA), formic acid (FA) and water (HPLC grade) were from Sigma Aldrich (Darmstadt, Germany). Milli-Q water was produced in-house to $18 \mathrm{M} \Omega / \mathrm{cm}$ quality, using a Milli-Q integral 3 system from Merck Millipore KGaA (Darmstadt, Germany). Normal glass vials $(1.5 \mathrm{~mL})$ were from Agilent (Santa Clara, CA, USA). Silanized glass vials $(1.5 \mathrm{~mL})$ were from Macherey-Nagel GmbH \& Co. KG (Duren, Germany), Polypropylene (PP) and Teflon tubes (1.5 mL) were from Merck Millipore KGaA (Darmstadt, Germany). Certified standard of okadaic acid (OA) from National Research Council Canada (Halifax, NS, Canada) was used in preliminary experiments. A non-certified PLTX standard (100 $\mu \mathrm{g}$; lot LAM7122) from Wako Chemicals GmbH (Neuss, Germany) was dissolved in $10 \mathrm{~mL}$ of $50 \%$ aqueous $\mathrm{MeOH}$ and used as stock solution $(10 \mu \mathrm{g} / \mathrm{mL})$ in all the experiments. We previously verified [8] that the authentic composition of this standard was $84 \%$ PLTX itself, $1.7 \%$ 42-hydroxypalytoxin and $14.3 \%$ other PLTX-like contaminants. Even so, in our calculations, we referred to the standard as consisting of $100 \%$ PLTX. Before each set of experiments described below, a seven-level PLTX calibration curve in 50\% aqueous $\mathrm{MeOH}(1000,500$, $250,125,62.5,31.2,15.6 \mathrm{ng} / \mathrm{mL}$ ) was used for quantitation. 


\subsection{Detection Methods}

Liquid chromatography-mass spectrometry at unit and high resolution (LC-MS and LC-HRMS)

LC-MS experiments were carried out using a 2.7-micrometer Poroshell 120 EC-C18, $2.1 \times 100 \mathrm{~mm}$ (Agilent, La Jolla, CA, USA) kept at $25^{\circ} \mathrm{C}$. Mobile phase was water (eluent A) and $95 \%$ acetonitrile/water (eluent B), both containing $30 \mathrm{mM}$ AA. Gradient elution at flow rate of $0.2 \mathrm{~mL} / \mathrm{min}$ was 20 to $100 \%$ B in $10 \mathrm{~min}$, hold for $5 \mathrm{~min}$ before dropping down to the initial conditions with a re-equilibration time of $10 \mathrm{~min}$. The analyses were carried out on the following two different instruments in triplicate:

Instrument 1 (Ifremer, France): An UFLC-XR Shimadzu LC system (Shimadzu, Japan) was coupled to a hybrid triple quadrupole/ion-trap mass spectrometer API 4000 Qtrap MS (ABSCIEX, Concord, ON, Canada) equipped with a TurbolonSpray ${ }^{\mathrm{TM}}$ ionization source. Source settings were curtain gas, $30 \mathrm{psi}$; ion spray, $5000 \mathrm{~V}$; turbogas temperature, $300{ }^{\circ} \mathrm{C}$; declustering potential, $56 \mathrm{~V}$; entrance potential, $10 \mathrm{~V}$; Gas 1 and Gas 2, 30 and $40 \mathrm{psi}$, respectively. MS detection of PLTX and OA was carried out in multiple reactions monitoring (MRM) mode (positive ions, Dwell time 500 or $250 \mathrm{~ms}$, for PLTX or OA, respectively) according to Table S1 and Figure S1. The sum of MRM peak areas was used to express peak intensity. Limit of Detection (LOD) was $15 \mathrm{ng} / \mathrm{mL}$. Analyst 1.5 software was used for integration of peaks and quantitation.

Instrument 2 (University of Napoli Federico II, Naples, Italy): An Ultimate 3000 quaternary LC system was coupled to a hybrid linear ion trap LTQ Orbitrap XL FTMS equipped with an ESI ION MAX ${ }^{\mathrm{TM}}$ source (Thermo-Fisher, Waltham, MA, USA). Full HRMS experiments for PLTX (positive ions) were acquired in the range $\mathrm{m} / \mathrm{z}$ 800-1400 and/or $\mathrm{m} / \mathrm{z}$ $1400-2000$ at a resolving power (RP) of 60,000 (FWHM at $\mathrm{m} / z$ 400). Source settings were spray voltage, $4.8 \mathrm{kV}$; capillary temperature, $360^{\circ} \mathrm{C}$; capillary voltage, $17 \mathrm{~V}$; tube lens voltage, $145 \mathrm{~V}$; sheath gas and auxiliary gas flow, 32 and 4 (arbitrary units), respectively. $\mathrm{HR}$ collision induced dissociation (CID) MS ${ }^{2}$ experiments were acquired at a RP 60,000 using collision energy, 35\%; isolation width, 3.0 Da; activation Q, 0.250 ; and activation time, $30 \mathrm{msec}$. Precursor ions were $[\mathrm{M}+\mathrm{H}+\mathrm{Ca}]^{3+}$ of PLTX $(\mathrm{m} / \mathrm{z}$ 906.8) and PLTX methyl ester $(\mathrm{m} / \mathrm{z}$ 869.4). Xcalibur software v2.0.7. was used to calculate elemental formulae of the mono-isotopic peak (mass tolerance $5 \mathrm{ppm}$ ). The isotopic pattern and Ring Double Bond equivalents (RDB) were considered in formula assignment. Extracted ion chromatograms (XICs) of $[\mathrm{M}+\mathrm{H}+\mathrm{Ca}]^{3+}$ of PLTX and/or its methyl ester and $[2 \mathrm{M}+\mathrm{H}+\mathrm{Ca}]^{3+}$ and $[3 \mathrm{M}+3 \mathrm{H}+\mathrm{Ca}]^{5+}$ for PLTX dimer and trimer, respectively, were obtained and used for calculating the percentage of each ion species using the following formula:

$$
\frac{A_{\text {dimer or trimer }}}{A_{\text {monomer }}+A_{\text {dimer }}+A_{\text {trimer }}} \times 100
$$

Peak area expressed peak intensity. Measured Limit of Detection (LOD) was $7 \mathrm{ng} / \mathrm{mL}$.

The preliminary evaporation experiment of OA and PLTX (Section 2.1) was performed on API 4000, whereas the study on the stability of PLTX in acids was performed on Orbitrap. All the other reported experiments were performed on API 4000 and repeated on Orbitrap.

\subsection{Sample Preparation}

Each PLTX sample was obtained from the PLTX stock solution $10 \mu \mathrm{g} / \mathrm{mL}$ by diluting it with the properly described mixture. The relative percentages of the water/methanol mixtures were reported according to the relevant mixture used for the PLTX stock solution dilution. In all explored cases, we considered the amount of methanol present in the initial solution negligible.

\subsubsection{Preliminary Evaporation Experiment on OA and PLTX}

PLTX $(50 \mu \mathrm{L})$ and OA $(50 \mu \mathrm{L})$ at equimolar concentration were mixed in $80 \%$ aqueous $\mathrm{MeOH}(900 \mu \mathrm{L})$ in glass vial, obtaining a mixture of PLTX $(125 \mathrm{ng} / \mathrm{mL})$ and OA 
( $25 \mathrm{ng} / \mathrm{mL}$ ). The mixture was dried down under $\mathrm{N}_{2}$-stream at room temperature. The residue, reconstituted in 50\% aqueous $\mathrm{MeOH}(300 \mu \mathrm{L})$, was analyzed using instrument 1 .

\subsubsection{Effect of Solvents on the Intensity of the $[\mathrm{M}+\mathrm{H}+\mathrm{Ca}]^{3+}$ Ion of PLTX}

PLTX stock solution was diluted (1:10) in glass vials in different blends: $\mathrm{H}_{2} \mathrm{O} 100 \% ; 10$, 30, 50 or $80 \%$ aqueous $\mathrm{MeOH} ; 80 \%$ aqueous $\mathrm{EtOH} ; 80 \%$ aqueous $\mathrm{IsoPrOH} ; 100 \% \mathrm{MeOH}$; $100 \% \mathrm{EtOH} ; 100 \%$ IsoPrOH. The solutions were analyzed using LC-HRMS (Instrument 2) $2 \mathrm{~h}$ after preparation.

\subsubsection{Effect of Drying Techniques on PLTX Recovery}

Aliquots of PLTX in $80 \%$ aqueous $\mathrm{MeOH}(125 \mathrm{ng} / \mathrm{mL} ; 1.0 \mathrm{~mL})$ were evaporated to dryness under $\mathrm{N}_{2}$-stream using a Multiple Nitrogen Evaporator (Liebisch Labortechnik, Germany) at room temperature and under vacuum using a Rotational Vacuum Concentrator RVC 2-18 (Martin Christ, Osterode am Harz, Germany) at $30^{\circ} \mathrm{C}$ for $5 \mathrm{~h}$. Residues were re-dissolved in 50\% aqueous $\mathrm{MeOH}(300 \mu \mathrm{L})$ and analyzed using both instruments. Experiments were performed in triplicate over 1 day and the relative data are expressed as mean \pm STD.

\subsubsection{Complete Drying in Different Materials}

Different samples of PLTX (125 ng/mL; $1.0 \mathrm{~mL})$ in 80\% aqueous $\mathrm{MeOH}, \mathrm{EtOH}$ and IsoPrOH and in pure $\mathrm{MeOH}, \mathrm{EtOH}$ and IsoPrOH were prepared using normal and silanized glass vials, PP and Teflon tubes. Three replicates of each solution in each vial/tube were dried-down under $\mathrm{N}_{2}$-stream and residues were re-dissolved in $1 \mathrm{~mL}$ of the original solvent and analyzed using instrument 1 .

In addition, the same number of aliquots of PLTX dried down in PP tubes were also re-dissolved in 50\% aqueous $\mathrm{MeOH}$ and analyzed using both LC-MS and LC-HRMS instruments.

Finally, aliquots $(1.0 \mathrm{~mL})$ of PLTX in $80 \%$ aqueous $\mathrm{MeOH}$ at four concentrations (62.5, 125,250 and $500 \mathrm{ng} / \mathrm{mL}$ ) were dried down under $\mathrm{N}_{2}$-stream at room temperature in Teflon tubes. Residues were re-dissolved either in $300 \mu \mathrm{L}$ or in $1 \mathrm{~mL}$ of $80 \%$ aqueous $\mathrm{MeOH}$ and analyzed using both instruments. Each experiment was reproduced in triplicate.

\subsubsection{Concentration in Different Materials}

Aliquots of PLTX (125 ng/mL; $1.0 \mathrm{~mL})$ in 80\% aqueous $\mathrm{EtOH}$, and IsoPrOH and in pure $\mathrm{MeOH}$, were prepared using normal and silanized glass vials, whereas aliquots of PLTX (125 ng/mL; $1 \mathrm{~mL}$ ) in 100\% MeOH, EtOH and IsoPrOH were prepared using PP and Teflon tubes and concentrated to $200 \mu \mathrm{L}$ under $\mathrm{N}_{2}$-stream and analyzed using instrument 1. Each experiment was reproduced in triplicate.

\subsubsection{Study on Stability of PLTX in Acids}

Three aliquots of PLTX $(1.0 \mu \mathrm{g} / \mathrm{mL} ; 1.0 \mathrm{~mL})$ in $80 \%$ aqueous $\mathrm{MeOH}$ (Control) and in $80 \%$ aqueous $\mathrm{MeOH}$ with $0.2 \% \mathrm{AA}$, or $0.1 \%$ TFA, or $2 \%$ FA were analyzed using LC$\operatorname{HRMS}^{n}(n=1,2)$ (instrument 2) 3 hours after preparation (day 0) and after 2 weeks (day 14). A second set of PLTX solutions $(125 \mathrm{ng} / \mathrm{mL} ; 1.0 \mathrm{~mL})$ in Teflon tubes was dried under $\mathrm{N}_{2}$-stream and residues, re-dissolved in $80 \%$ aqueous $\mathrm{MeOH}(1.0 \mathrm{~mL})$, analyzed using both instruments. A third set of PLTX solutions $(5 \mu \mathrm{g} / \mathrm{mL} ; 5.0 \mathrm{~mL})$ in glass tubes was kept at $60{ }^{\circ} \mathrm{C}$ for $1 \mathrm{~h}$ and analyzed using both instruments. 
Supplementary Materials: The following are available online at https: / www.mdpi.com/article/ 10.3390/toxins13090650/s1, Figure S1: Planar structure of assorted palytoxins, Figure S2: HRMS spectrum of PLTX in 100\% water, Figure S3, HRMS 2 spectrum of PLTX methyl ester, Table S1: MS parameters and transitions used in Multiple Reaction Monitoring (MRM) experiments, Table S2: The intensity of PLTX mass peaks diluted in different solvents and blends, Table S3: Recoveries of PLTX following complete drying in PP and Teflon tubes, normal and silanized glass, Table S4: Recoveries of PLTX at different initial concentration following complete drying in Teflon tubes, Table S5: Recoveries of PLTX following concentration in PP and Teflon tubes, normal and silanized glass vials.

Author Contributions: Conceptualization, A.M., M.V., L.T., P.C., P.H. and C.D.; methodology, A.M. and Z.Z.; formal analysis, A.M., Z.Z., L.T.; investigation, A.M., Z.Z. and L.T.; resources, M.V., P.H. and C.D.; data curation, A.M., M.V. and L.T.; writing-original draft preparation, A.M., L.T. and C.D.; writing-review and editing, A.M., M.V., L.T., P.C., P.H. and C.D.; supervision, M.V., L.T., C.D. and P.H.; project administration, P.H. and C.D.; funding acquisition, P.H. and C.D. All authors have read and agreed to the published version of the manuscript.

Funding: This research was funded by UniNA and Compagnia di San Paolo in the frame of Programme STAR Linea 12013 (VALTOX, Napoli_call2013_08) and by Regione Campania in the frame of the Monitoring Program of Ostreopsis ovata along the Campania Coasts. Z. Zendong and P. Hess were partly funded by the Regional Council of the Pays de la Loire through the COSELMAR project (2012-2017).

Institutional Review Board Statement: Not applicable.

Informed Consent Statement: Not applicable.

Data Availability Statement: Not applicable.

Acknowledgments: We are grateful to Takeshi Yasumoto (Japan) for informal discussions on potential solubility issues with such large toxins.

Conflicts of Interest: There is no conflict of interest pending on this paper.

\section{References}

1. Moore, R.E.; Scheuer, P.J. Palytoxin: A new marine toxin from a Coelenterate. Science 1971, 172, 495-498. [CrossRef]

2. Uemura, D.; Hirata, Y.; Iwashita, T.; Naoki, H. Studies on palytoxins. Tetrahedron 1985, 41, 1007-1017. [CrossRef]

3. Kerbrat, A.S.; Amzil, Z.; Pawlowiez, R.; Golubic, S.; Sibat, M.; Darius, H.T.; Chinain, M.; Laurent, D. First evidence of palytoxin and 42-hydroxy-palytoxin in the marine cyanobacterium Trichodesmium. Mar. Drugs 2011, 9, 543-560. [CrossRef] [PubMed]

4. Ciminiello, P.; Dell'Aversano, C.; Forino, M.; Tartaglione, L. Marine toxins in Italy: The more you look, the more you find. Eur. J. Org. Chem. 2014, 7, 1357-1369. [CrossRef]

5. Tartaglione, L.; Mazzeo, A.; Dell'Aversano, C.; Forino, M.; Giussani, V.; Capellacci, S.; Penna, A.; Asnaghi, V.; Faimali, M.; Chiantore, M.; et al. Chemical, molecular, and eco-toxicological investigation of Ostreopsis sp. from Cyprus Island: Structural insights into four new ovatoxins by LC-HRMS/MS. Anal. Bioanal. Chem. 2016, 408, 915-932. [CrossRef] [PubMed]

6. Ciminiello, P.; Dell'Aversano, C.; Forino, M. Chemistry of palytoxin and its analogues. In Phycotoxins: Chemistry and Biochemistry, 2nd ed.; Botana, L., Alfonso, A., Eds.; John Wiley \& Sons Ltd.: New York, NY, USA, 2015.

7. Onuma, Y.; Satake, M.; Ukena, T.; Roux, J.; Chanteau, S.; Rasolofonirina, N.; Ratsimaloto, M.; Naoki, H.; Yasumoto, T. Identification of putative palytoxin as the cause of clupeotoxism. Toxicon 1999, 37, 55-65. [CrossRef]

8. Ciminiello, P.; Dell'Aversano, C.; Dello Iacovo, E.; Fattorusso, E.; Forino, M.; Tartaglione, L.; Benedettini, G.; Onorari, M.; Serena, F.; Battocchi, C.; et al. First Finding of Ostreopsis cf. ovata Toxins in Marine Aerosols. Environ. Sci. Technol. 2014, 48, 3532-3540. [CrossRef] [PubMed]

9. Tartaglione, L.; Dell'Aversano, C.; Mazzeo, A.; Forino, M.; Wieringa, A.; Ciminiello, P. Determination of Palytoxins in Soft Coral and Seawater from a Home Aquarium. Comparison between Palythoa- and Ostreopsis-Related Inhalatory Poisonings. Environ. Sci. Technol. 2016, 50, 1023-1103. [CrossRef] [PubMed]

10. Pelin, M.; Brovedani, V.; Sosa, S.; Tubaro, A. Palytoxin-containing aquarium soft corals as an emerging sanitary problem. Mar. Drugs 2016, 14, 33. [CrossRef]

11. Poli, M.; Ruiz-Olvera, P.; Nalca, A.; Ruiz, S.; Livingston, V.; Frick, O.; Dyer, D.; Schellhase, C.; Raymond, J.; Kulis, D.; et al. Toxicity and Pathophysiology of Palytoxin Congeners after Intraperitoneal and Aerosol Administration in Rats. Toxicon 2018, 150, 235-250. [CrossRef]

12. Ito, E.; Yasumoto, T. Toxicological studies on palytoxin and ostreocin-D administered to mice by three different routes. Toxicon 2009, 54, 244-251. [CrossRef] [PubMed] 
13. Ciminiello, P.; Dell'Aversano, C.; Dello Iacovo, E.; Fattorusso, E.; Forino, M.; Grauso, L.; Tartaglione, L.; Florio, C.; Lorenzon, P.; De Bortoli, M.; et al. Stereostructure and Biological Activity of 42-Hydroxy-palytoxin: A New Palytoxin Analogue from Hawaiian Palythoa Subspecies. Chem. Res. Toxicol. 2009, 22, 1851-1859. [CrossRef] [PubMed]

14. Crinelli, R.; Carloni, E.; Giacomini, E.; Penna, A.; Dominici, S.; Battocchi, C.; Ciminiello, P.; Dell'Aversano, C.; Fattorusso, E.; Forino, M.; et al. Palytoxin and an Ostreopsis Toxin Extract Increase the Levels of mRNAs Encoding Inflammation-Related Proteins in Human Macrophages via p38 MAPK and NFkB. PLoS ONE 2012, 7, e38139. [CrossRef]

15. Ciminiello, P.; Dell'Aversano, C.; Dello Iacovo, E.; Forino, M.; Tartaglione, L.; Pelin, M.; Sosa, S.; Tubaro, A.; Chaloin, O.; Poli, M.; et al. Stereoisomers of 42-hydroxy palytoxin from Hawaiian Palythoa toxica and P. tuberculosa: Stereostructure elucidation, detection, and biological activities. J. Nat. Prod. 2014, 77, 351-357. [CrossRef]

16. Pelin, M.; Forino, M.; Brovedani, V.; Tartaglione, L.; Dell'Aversano, C.; Pistocchi, R.; Poli, M.; Sosa, S.; Florio, C.; Ciminiello, P.; et al. Ovatoxin-a, a Palytoxin Analogue Isolated from Ostreopsis cf. ovata Fukuyo: Cytotoxic Activity and ELISA Detection. Environ. Sci. Technol. 2016, 50, 1544-1551. [CrossRef]

17. Ciminiello, P.; Dell'Aversano, C.; Dello Iacovo, E.; Fattorusso, E.; Forino, M.; Grauso, L.; Tartaglione, L.; Guerrini, F.; Pezzolesi, L.; Pistocchi, R.; et al. Isolation and structure elucidation of Ovatoxin-a, the major toxin produced by Ostreopsis ovata. J. Am. Chem. Soc. 2012, 134, 1869-1875. [CrossRef]

18. Brissard, C.; Herrenknecht, C.; Sechet, V.; Herve, F.; Pisapia, F.; Harcouet, J.; Lemee, R.; Chomerat, N.; Hess, P.; Amzil, Z. Complex Toxin Profile of French Mediterranean Ostreopsis cf. ovata Strains, Seafood Accumulation and Ovatoxins Prepurification. Mar. Drugs 2014, 12, 2851-2876. [CrossRef] [PubMed]

19. Zendong, Z.; Herrenknecht, C.; Abadie, E.; Brissard, C.; Tixier, E.; Mondeguer, F.; Sechet, V.; Amzil, Z.; Hess, P. Extended evaluation of polymeric and lipophilic sorbents for passive sampling of marine toxins. Toxicon 2014, 91, 57-68. [CrossRef] [PubMed]

20. Taylor, T.J.; Gerald, P.W.; Abram, F.B.; Mereish Kay, M.A. Non-specific binding of palytoxin to plastic surfaces. Toxicol. Lett. 1991, 57, 291-296. [CrossRef]

21. Ciminiello, P.; Dell'Aversano, C.; Dello Iacovo, E.; Fattorusso, E.; Forino, M.; Tartaglione, L.; Rossi, R.; Soprano, V.; Capozzo, D.; Serpe, L. Palytoxin in seafood by liquid chromatography tandem mass spectrometry: Investigation of extraction efficiency and matrix effect. Anal. Bioanal. Chem. 2011, 401, 1043-1050. [CrossRef]

22. Amzil, Z.; Sibat, M.; Chomerat, N.; Grossel, H.; Miralles, F.M.; Lemee, R.; Nezan, E.; Sechet, V. Ovatoxin-a and Palytoxin Accumulation in Seafood in Relation to Ostreopsis cf. ovata Blooms on the French Mediterranean Coast. Mar. Drugs 2012, 10, 477-496. [CrossRef]

23. Inuzuka, T.; Fujisawa, T.; Arimoto, H.; Uemura, D. Molecular shape of palytoxin in aqueous solution. Org. Biomol. Chem. 2007, 5, 897-899. [CrossRef]

24. Yoon, R.; Vivek, S. Effects of Short-Chain Alcohols and Pyridine on the Hydration Forces between Silica Surfaces. J Colloid Interface Sci. 1998, 204, 179-186. [CrossRef]

25. Paridaa, S.K.; Dashb, S.; Patela, S.; Mishra, B.K. Adsorption of organic molecules on silica surface. Adv. Colloid Interface Sci. 2006, 121, 77-110. [CrossRef]

26. Henry, C.; Minier, J.-P. Colloidal particle resuspension: On the need for refined characterization of surface roughness. J. Aerosol Sci. 2018, 118, 1-13. [CrossRef]

27. Movafaghi, S.; Wu, H.; Francino Urdániz, I.M.; Bull, D.S.; Kelly, M.D.; Randolph, T.W.; Goodwin, A.P. The Effect of Container Surface Passivation on Aggregation of Intravenous Immunoglobulin Induced by Mechanical Shock. Biotechnol. J. 2020. [CrossRef]

28. Roberts, C.J. Therapeutic Protein Aggregation: Mechanisms, Design, and Control. Trends Biotechnol. 2014, 32, 372-380. [CrossRef]

29. Usami, M.; Satake, M.; Ischida, S. Palytoxin analogues from the dinoflagellate Ostreopsis siamensis. J. Am. Chem. Soc. 1995, 117, 5389-5390. [CrossRef]

30. McCalley, D.V. Study of retention and peak shape in hydrophilic interaction chromatography over a wide pH range. J. Chromatogr. A 2015, 14, 41-49. [CrossRef] [PubMed]

31. Jauffrais, T.; Herrenknecht, C.; Séchet, V.; Sibat, M.; Tillmann, U.; Krock, B.; Kilcoyne, J.; Miles, C.; McCarron, P.; Amzil, Z.; et al. Quantitative analysis of azaspiracids in Azadinium spinosum cultures. Anal. Bioanal. Chem. 2012, 403, 833-846. [CrossRef] [PubMed]

32. Ciminiello, P.; Dell'Aversano, C.; Dello Iacovo, E.; Fattorusso, E.; Forino, M.; Grauso, L.; Tartaglione, L. High resolution LC-MSn fragmentation pattern of palytoxin as template to gain new insights into ovatoxin-A structure. The key role of calcium in MS behavior of palytoxins. J. Am. Soc. Mass Spectrom. 2012, 23, 952-963. [CrossRef] [PubMed]

33. Ciminiello, P.; Dell'Aversano, C.; Dello Iacovo, E.; Fattorusso, E.; Forino, M.; Tartaglione, L.; Battocchi, C.; Crinelli, R.; Carloni, E.; Magnani, M.; et al. The unique toxin profile of a Mediterranean Ostreopsis cf. ovata strain. HR LC-MSn characterization of ovatoxin-f, a new palytoxin congener. Chem. Res. Toxicol. 2012, 25, 1243-1252. [CrossRef] [PubMed]

34. Brissard, C.; Hervé, F.; Sibat, M.; Séchet, V.; Hess, P.; Amzil, Z.; Herrenknecht, C. Characterization of ovatoxin-h, a new ovatoxin analog, and evaluation of chromatographic columns for ovatoxin analysis and purification. J. Chromatogr. A 2015, 3, 87-101. [CrossRef] [PubMed] 
35. García-Altares, M.; Tartaglione, L.; Dell'Aversano, C.; Carnicer, O.; de la Iglesia, P.; Forino, M.; Diogène, J.; Ciminiello, P. The novel ovatoxin-g and isobaric palytoxin (so far referred to as putative palytoxin) from Ostreopsis cf. ovata (NW Mediterranean

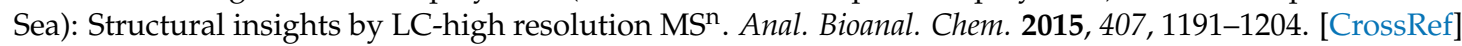

36. Katrizky, A. Advances in Heterocyclic Chemistry, 1st ed.; Academic Press: New York, NY, USA, 2014 ; ISBN 9780124202092. 